(C) 2017 IEEE. Personal use of this material is permitted. Permission from IEEE must be obtained for all other uses, in any current or future media, including reprinting/republishing this material for advertising or promotional purposes, creating new collective works, for resale or redistribution to servers or lists, or reuse of any copyrighted component of this work in other works. 


\section{Decision Making on Adoption of Cloud Computing in E-Commerce Using Fuzzy TOPSIS}

\author{
Osama Sohaib \\ School of Systems, Management and Leadership \\ Faculty of Engineering and IT \\ University of Technology Sydney (UTS) \\ Ultimo, NSW 2007, Australia \\ Osama.Sohaib@uts.edu.au
}

\author{
Mohsen Naderpour \\ Centre for Artificial Intelligence \\ School of Systems, Management and Leadership \\ Faculty of Engineering and IT \\ University of Technology Sydney (UTS) \\ Ultimo, NSW 2007, Australia \\ Mohsen.Naderpour@uts.edu.au
}

\begin{abstract}
Cloud computing promises enhanced scalability, flexibility, and cost-efficiency. In practice, however, there are many uncertainties about the usage of cloud computing resources in the e-commerce context. As e-commerce is dependent on a reliable and secure online store, it is important for decision makers to adopt an optimal cloud computing mode (Such as SaaS, PaaS and IaaS). This study assesses the factors associated with cloud-based e-commerce based on TOE (technological, organizational, and environmental) framework using multicriteria decision-making technique (Fuzzy TOPSIS). The results show that Fuzzy TOPSIS (Technique for Order of Preference by Similarity to Ideal Solution) approach proposes software-as-aservice (SaaS) as the best choice for e-commerce business.
\end{abstract}

Keywords-E-commerce; Cloud Computing; MCDM; Fuzzy TOPSIS

\section{INTRODUCTION}

The environment of e-commerce change rapidly. Such as, competition, demand for sustainability and participation, rapid development of cloud computing offerings, the social web, etc. [1]. In order to survive in this rapidly changing environment, global competition places huge pressure on ecommerce firms to enhance productivity and increase profitability. This has encouraged e-commerce managers to adopt the most current technologies that enable them to improve and sustain competitive advantage. Cloud computing has the potential to be the solution to gain a competitive advantage and allows e-commerce firms to become more efficient and productive. E-commerce, which adopts cloud computing technologies, is being increasingly renowned as a main way for transforming all facets of e-commerce operations and services. However, many concerns about quality of service, transparency, cost and security prevent companies from adopting cloud computing [1-3].

Cloud computing provides opportunities for businesses to increase their productivity and reduce their operations and maintenance cost while providing products to their customers [4]. However, the challenge remains to conclude the factors that lead businesses to adopt cloud-based e-commerce solution. In order to select the right solution of the ecommerce needs, e-commerce managers must understand the strength and weakness of cloud computing models. Cloud service models as per NIST (National Institute of Standards and Technology) [5] are IaaS (infrastructure as a service), PaaS (platform as a service), and SaaS (software as a service) describe how cloud services are made available to the clients. For instance, an e-commerce firm can use an IaaS model to purchase resources (such as servers, storage, network and operating systems) as a service on demand. PaaS provides a pre-built application platform to the client; business requisition resources as they need them, rather than investing in underlying infrastructure for their applications. Alternatively, businesses can quickly launch e-commerce sites without worrying about server configurations and software updates. In practice, however, there are many uncertainties about the usage of cloud-based resources in e-commerce [6]. As e-commerce is dependent on reliable secure online stores [2], it is important to for managers or decision-makers to map back the different cloud service models to the business financial resources and technology requirements.

The purpose of this study is to analyze e-commerce manager's decision-making in terms of the adoption of public cloud computing modes (SaaS, PaaS and IaaS) and its determinants in the context of e-commerce. Following the main aim, the research question is: What is the impact of technological, organizational, and environmental context factors on the adoption of cloud-based e-commerce? This paper applied Tornatzky and Fleischer [7] TechnologyOrganization-Environment (TOE) framework to investigate the factors influencing cloud computing modes (SaaS, PaaS and IaaS) adoption using Fuzzy TOPSIS (Technique for Order of Preference by Similarity to Ideal Solution), a popular MultiCriteria Decision Making (MCDM) technique.

The study is organized as: First, background information about e-commerce, cloud computing, TechnologyOrganization-Environment (TOE) framework, and MCDM are provided. Then the research method is explained followed by case study analysis and results. Finally, the study concludes.

\section{BACKGROUND AND LITERATURE REVIEW}

This section discusses some background information and related studies about e-commerce, cloud computing, TOE framework and multi criteria decision making.

\section{A. E-Commerce}




\section{Accepted Manuscript: 2017 IEEE International Conference on Fuzzy Systems (FUZZ-IEEE 2017)}

E-commerce refers to the selling and buying of products or services over the Internet. The use of technology is increased in our daily life. The e-commerce is such kind of utilization of technology that has transformed the e-commerce and business to a technological dimension. The growth of business also depends on this factor that how much that organization uses technology. There are various applications of technology and computations in the field of e-commerce. The analysis of data and advantageous features extraction is not possible on generic data [8]. E-commerce allows a helpful analysis of the data which further aids in the business intelligence, product suggestions, and recommendations, and the fraud detection [9]. There are different e-commerce models that are used by the multinational corporations around the globe, these include; B2B (business to business), B2C (business to consumer), C2C (consumer-to-consumer) etc.

\section{B. Cloud Computing}

The cloud computing is helpful in the infrastructure of the business. The cloud computing involves various technologies, comprised of hardware and software with the concept of distributed computing, virtualization, Internet systems management, communication networks, big data services, and data analytics. The cloud computing is feasible and low-cost solution for an organization and business services. Servers can be public, private or the hybrid involving protected approaches. However, there can be also various threats in the virtualization by the cloud computing, including intrusion and unauthentic services [10]. The presentation of advancement in the affiliation helps in virtualizing various business strategies [11]. There are different cloud computing service models; SaaS, PaaS and IaaS. SaaS or Software-as-a-Service is the capability that is provided to the client for the purpose of using the applications from the service provider on the cloud infrastructure. PaaS or Platform-as-a-Service is the capability that is provided to the client to deploy on to the cloud infrastructure that is created by the consumer while IaaS or Infrastructure-as-a-Service is the capability provided to the client for processing, storing and accessing the networks and the consumer is able to run arbitrary software applications. Fig. 1 shows the difference between different cloud service models [12].

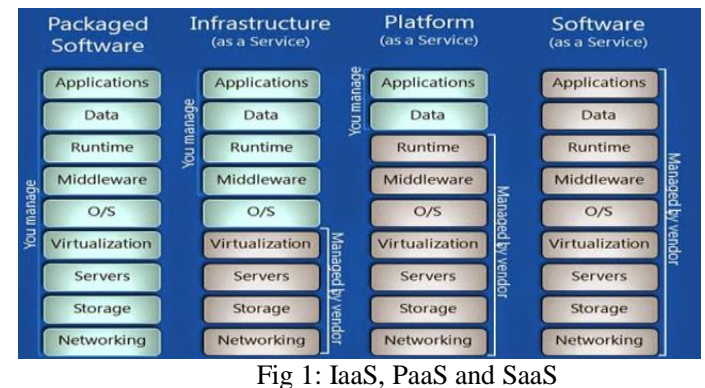

A cloud computing can provide the virtual infrastructure for utility computing integrating applications. Cloud computing that offers utility-based model will enable businesses and users to access applications on demand anytime, anyplace and anywhere [13]. For example, in the
Security \&
Privacy

context of e-commerce consumer the cloud system will transform data using smart devices into insight and drive productive actions from these insights.

\section{Technology-Organization - Environment}

For the purpose of this study we have adopted Technology-Organization-Environment (TOE) framework [7], which assumes a generic set of factors to predict the possibility of cloud-based e-commerce adoption. The theory suggests that adoption is influenced by technology development, organizational conditions, and industry environment.

\section{1) Technological Context}

The TOE framework's technology context denotes to internal and external technologies which are appropriate for the organisation. The adoption of technology can be complex, yet it is highly compatible with a business and if managed properly with the respective persons, can provide high growth in the business [14]. Decisions to adopt cloud technology are determined by innovations fit with the existing technology landscape [7]. Frequently used factors are relative advantage, complexity, compatibility, accessibility, reliability, security and privacy and scalability [15-17]. Table I describes each factor.

TABLE I: TECHNOLOGICAL FACTORS DEFINITION

\begin{tabular}{ll}
\hline Factor & Definition \\
\hline Relative & "the degree to which an innovation is perceived as being \\
advantage & better than the idea it supersedes" [18]. Cloud computing \\
& has an advantage for businesses to establish new services \\
& without managing or owning computer resources [14]. \\
& Such as cloud computing relative advantages for e- \\
& commerce are scalability, pay-as-you-go payment model \\
& and efficiency [19]. E-commerce firms should assess the \\
& relative advantages of cloud computing such as costs \\
optimisation. & The perceived degree of difficulty of understanding and \\
using a system [16]. For-example, if the complex aspects \\
of the cloud computing are hidden from the client, this will \\
create higher uncertainty related to successful adoption \\
[14]. \\
"the degree to which an innovation is perceived as being \\
consistent with the existing value, past experiences, and \\
needs of receivers" [16]. This means that the cloud \\
technologies are in align with the different software \\
platform, the organization will be able to adopt the benefits \\
of cloud computing. \\
Security denotes the level of security procedures in place \\
to protect the system from unauthorized access. Privacy \\
refers to the confidentiality of user information. The \\
decision on selecting a cloud provider is very often \\
influenced by company requirements in the areas of \\
security, and privacy [17, 20]. Businesses have to be sure \\
that their data and applications in the Cloud, are \\
adequately protected against unauthorized access. \\
The ability of the cloud service to keep functioning with \\
particular level of performance over time. This means that \\
the customer can trust the cloud service for guaranteed \\
availability. The provider makes this form of commitment \\
mostly in form of Service Level Agreements (SLAs) [20]. \\
The ability of the cloud computing to manage increasing \\
amounts of resources. Due to the extensive usage mobile \\
applications, on demand services, transactions and \\
workloads can rise significantly and require scalable IT \\
structites [20].
\end{tabular}




\section{Accepted Manuscript: 2017 IEEE International Conference on Fuzzy Systems (FUZZ-IEEE 2017)}

\section{2) Organizational Context}

The TOE framework's organizational context refers to the characteristics and resources of an organisation. The organisation readiness is very good for a business and if oversaw legitimately with the individual people, can give high development in the business. The firm size of an organization plays a role in the advancement of the organization, yet it should not be high enough or low enough. For this study we have selected the organisation readiness, firm size and top management support $[17,21]$. Table II shows decription.

TABLE II: ORGANISATIONAL FACTORS DEFINITION

\begin{tabular}{|c|c|}
\hline Factor & Definition \\
\hline $\begin{array}{l}\text { Organizational } \\
\text { readiness }\end{array}$ & $\begin{array}{l}\text { This refers to "managers perception and evaluation of the } \\
\text { degree to which they believe that their organization has } \\
\text { the awareness, resources, commitment, and governance' } \\
\text { to adopt an IT" [21]. This involves IT infrastructure and } \\
\text { human resources (skills) required to adopt cloud } \\
\text { computing.. }\end{array}$ \\
\hline Firm size & $\begin{array}{l}\text { The firm size has been accepted as important facilitator } \\
\text { for the adoption of technology innovations [7]. The } \\
\text { investment in cloud computing of small to medium and } \\
\text { large firms differs significantly [16]. }\end{array}$ \\
\hline $\begin{array}{l}\text { Top } \\
\text { management } \\
\text { support }\end{array}$ & $\begin{array}{l}\text { This factor contribute to the adoption of innovations by } \\
\text { creating a productive environment and by providing } \\
\text { resources [16]. Top management support for the cloud } \\
\text { computing transformation is important. }\end{array}$ \\
\hline
\end{tabular}

\section{3) Environmental Context}

The TOE framework's environmental context relates to "a firm conducts its business - its industry, competitors, access to resources supplied by others, and dealing with the government" [7, 16]. The effective communications with the vendors, partners, and the competitors need to be managed optimally so the management is not affected, and the maintenance of environmental sustainability is attained [22]. For this study we have selected the competitive pressure, cost and trading partner pressure and government regulatory environment $[17,21]$. Table III explain each factor.

TABLE III: ENVIROMENTAL FACTORS DEFINITION

\begin{tabular}{|c|c|}
\hline Factor & Definition \\
\hline $\begin{array}{l}\text { Competitive } \\
\text { pressure }\end{array}$ & $\begin{array}{l}\text { The degree of pressure that an organisation faces from } \\
\text { competitors. More competition means more adoption of } \\
\text { innovation. }\end{array}$ \\
\hline $\begin{array}{l}\text { Trading } \\
\text { partner } \\
\text { pressure }\end{array}$ & $\begin{array}{l}\text { The pressure from trading partners to implement and } \\
\text { adopt a technology [21]. E-commerce requires network } \\
\text { externalities with trading partners (such as consumers, } \\
\text { dealers, suppliers and vendors) to ensure electronic } \\
\text { interactions and transactions along the value chain. }\end{array}$ \\
\hline $\begin{array}{l}\text { Government } \\
\text { regulatory } \\
\text { environment }\end{array}$ & $\begin{array}{l}\text { Cloud computing adoption is affected by government } \\
\text { legislations [19]. Such as if there are no governmental } \\
\text { regulations that can support the business in the event of a } \\
\text { data breach. The lack of standards might obstruct } \\
\text { adoption decisions. }\end{array}$ \\
\hline
\end{tabular}

\section{Multi-Criteria Decision Making (MCDM)}

MCDM (Multi-criteria decision making) denotes decision making in the presence of multiple and conflicting criteria [23]. MCDM involves both quantitative and qualitative factors are considered as a complex decision-making tool [24]. There are several MCDM methods have been recommended to choosing the best feasible options [24]. To solve real-world decision problems using MCDA techniques, the TOPSIS
(Technique for Order Preference by Similarity to Ideal Solution) developed by Hwang and Yoon [25] continues to work acceptably across different application areas [26]. However, in most real world decision problems at both tactical and strategic levels often involves fuzziness in its criteria and decision makers' judgments [23]. This kind of decision problems is referring fuzzy multi-criteria decision making (FMCDM) [23]. FMCDM deals with the large number of criteria that decision makers are expected to incorporate in their actions. Such as fuzzy TOPSIS method aims to choose alternatives that have the short distance fuzzy positive ideal solution and are extreme from the fuzzy negative ideal solution [23].

\section{1) MCDM Problem}

A typical MCDM problem based on $m$ alternatives $\left(\mathrm{A}_{1}, \mathrm{~A}_{2}\right.$, $\left.\ldots, A_{m}\right)$ and $n$ criteria $\left(C_{1}, C_{2}, \ldots, C_{n}\right)$ are presented as:

$$
\mathrm{X}=\left[\mathrm{X}_{\mathrm{ij}}\right]_{\mathrm{m} * \mathrm{n}}, \mathrm{W}=\left[\mathrm{w}_{\mathrm{j}}\right]_{\mathrm{n}}
$$

where $X$ is the decision matrix, $\mathrm{x}_{\mathrm{ij}}$ is the performance of the ith alternative with respect to the $\mathrm{jth}$ criterion, $\mathrm{W}$ is the weight vector, and $w_{j}$ is the weight of the jth criterion. The original decision matrix $\mathrm{X}$ is typically incomparable because different criteria are expressed using different units of measure. Therefore, data should be transformed into comparable values using a normalization procedure. The weight vector $\mathrm{W}$ has a large effect on the ranking results of alternatives. It is usually fixed using an expert's assignment or the analytic hierarchy process (AHP) method [27].

\section{2) TOPSIS Method}

According to this technique, the best alternative would be the one that is nearest to the positive-ideal solution and farthest from the negative ideal solution. The positive-ideal solution is a solution that maximizes the benefit criteria and minimizes the cost criteria, whereas the negative ideal solution maximizes the cost criteria and minimizes the benefit criteria. In short, the positive-ideal solution is composed of all best values attainable from the criteria, whereas the negative ideal solution consists of all worst values attainable from the criteria [28]. The TOPSIS method consists of the following steps [28]:

- Step 1. Normalize the decision matrix:

$$
r_{i j}=\frac{x_{i j}}{\sqrt{\sum_{i=1}^{m} x_{i j}^{2}}}, i=1,2, \ldots, m ; j=1,2, \ldots, n
$$

where ${ }^{r_{i j}}$ denotes the normalized value of the jth criterion for the ith alternative $A_{i}$.

- Step 2. Calculate the weighted normalized decision matrix: $\mathrm{v}_{\mathrm{ij}}=\mathrm{r}_{\mathrm{ij}} * \mathrm{w}_{\mathrm{j}}, \mathrm{i}=1,2, \ldots, \mathrm{m} ; \mathrm{j}=1,2, \ldots, \mathrm{n}$
where ${ }^{{ }_{j}}$ is the weight of the $\mathrm{jth}$ criterion or attribute.

- Step 3. Determine the positive ideal and negative ideal solutions:

$$
A^{+}=\left(v_{1}^{+}, v_{2}^{+}, \ldots, v_{n}^{+}\right), \quad A^{-}=\left(v_{1}^{-}, v_{2}^{-}, \ldots, v_{n}^{-}\right)
$$
where $\mathrm{A}^{+}$denotes the positive ideal solution, and $\mathrm{A}^{-}$denotes the negative ideal solution. If the jth criterion is a beneficial criterion, then $\mathrm{v}_{\mathrm{j}}^{+}=\max \left\{\mathrm{v}_{\mathrm{ij}}, \mathrm{i}=1,2, \ldots, \mathrm{m}\right\} \quad$ and $\mathrm{v}_{\mathrm{j}}^{-}=\min \left\{\mathrm{v}_{\mathrm{ij}}\right.$, $\mathrm{i}=1,2, \ldots, \mathrm{m}\}$. In contrast, if the $\mathrm{jth}$ criterion is a cost 


\section{Accepted Manuscript: 2017 IEEE International Conference on Fuzzy Systems (FUZZ-IEEE 2017)}

criterion, then $\quad \mathrm{v}_{\mathrm{j}}^{+}=\min \left\{\mathrm{v}_{\mathrm{ij}}, \quad \mathrm{i}=1,2, \ldots, \mathrm{m}\right\}$ and $\mathrm{v}_{\mathrm{j}}^{-}=\max \left\{\mathrm{v}_{\mathrm{ij}}, \mathrm{i}=1,2, \ldots, \mathrm{m}\right\}$.

- Step 4. Calculate the distances from each alternative to a positive ideal solution and a negative ideal solution:

$$
\begin{gathered}
D_{i}^{+}=\sqrt{\sum_{j=1}^{n}\left(v_{i j}-v_{j}^{+}\right)^{2}}, i=1,2, \ldots, m \\
D_{i}^{-}=\sqrt{\sum_{j=1}^{n}\left(v_{i j}-v_{j}^{-}\right)^{2}}, i=1,2, \ldots, m
\end{gathered}
$$

where $\mathrm{D}_{\mathrm{i}}^{+}$denotes the distance between the $i$ th alternative and the positive ideal solution, and $\mathrm{D}_{\mathrm{i}}^{-}$denotes the distance between the $i$ th alternative and the negative ideal solution.

- Step 5. Calculate relative closeness to the ideal solution.

$$
\mathrm{C}_{\mathrm{i}}=\frac{\mathrm{D}_{\mathrm{i}}^{-}}{\mathrm{D}_{\mathrm{i}}^{+}+\mathrm{D}_{\mathrm{i}}^{-}}, \mathrm{i}=1,2, \ldots, \mathrm{m}
$$

- Step 6. Rank the alternatives according to $C_{i}$ values.

3) Fuzzy TOPSIS Method

Fuzzy TOPSIS and its extensions are developed to solve ranking and justification problems. This study uses triangular fuzzy number for its simplicity for decision-makers to use and calculate. In addition, modeling using triangular fuzzy numbers has proven to be an effective way for formulating decision problems where the information available is subjective and imprecise [28].

Definition 1 (Fuzzy set): A fuzzy set A is defined in terms of a universal set $X$ by a membership function that assigns to each element $x \in X$ a value $\mu_{A}(x)$ in the interval $[0,1]$, i.e. $A: X \rightarrow[0,1][29]$.

Definition 2 (Fuzzy number): A fuzzy set $A$ in $\mathbb{R}$ satisfies the following conditions [30]:

- A is normal.

- $\mathrm{A}_{\alpha}$ is a closed interval for every $\alpha \in(0,1]$.

- The support of A is bounded.

Fig. 2 represents the general characteristic of a fuzzy number $\mathrm{A}$ where $\mu_{\mathrm{A}}(\mathrm{x})$ denotes the membership function of $\mathrm{x}$ in the fuzzy set. This shape of fuzzy number is referred to as triangular.

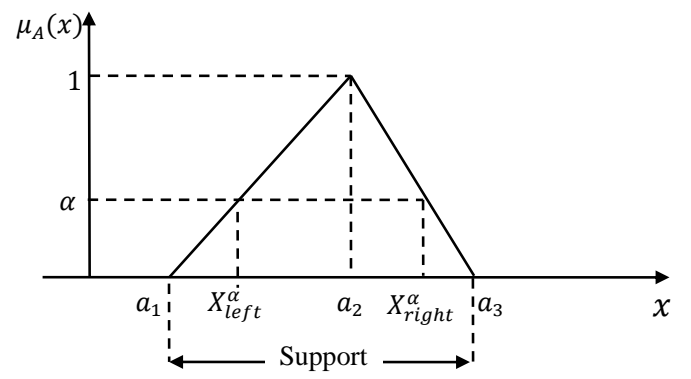

Fig 2. A Fuzzy number.

Definition 3 (Linguistic variable): Linguistic variable is a variable whose values are words or sentences in a natural or artificial language [31]. Linguistic variable is characterized by (X, T, U, M) where:

- $X$ is the name of the linguistic variable (e.g. Weather temperature)

- $\mathrm{T}$ is the set of linguistic values that $\mathrm{X}$ can take (e.g. $\mathrm{T}=$ \{Cold, Pleasant, Hot $\}$ )
- $\mathrm{U}$ is the actual physical domain in which the linguistic variable $\mathrm{X}$ takes its quantitative (crisp) values (e.g. $\mathrm{U}=$ $\left[-20,40{ }^{\circ} \mathrm{C}\right)$.

- $\mathrm{M}$ is a semantic rule that relates each linguistic value in $\mathrm{T}$ with a fuzzy set in $\mathrm{U}$; (e.g. $\mathrm{M}$ relates 'Cold', 'Pleasant', and 'Hot' with the membership functions).

Definition 4 (Vertex method): Let $\tilde{a}=\left(a_{1}, a_{2}, a_{3}\right)$ and $\tilde{b}=$ $\left(b_{1}, b_{2}, b_{3}\right)$ be two triangular fuzzy numbers, the vertex method calculates the distance between them as follows:

$$
d(\tilde{a}, \tilde{b})=\sqrt{\frac{1}{3}\left[\left(a_{1}-b_{1}\right)^{2}+\left(a_{2}-b_{2}\right)^{2}+\left(a_{3}-b_{3}\right)^{2}\right]}
$$

Considering above definitions, fuzzy TOPSIS steps are outlined as follows [23]:

- Step 1: Select the linguistic values $\widetilde{X}=\left\{\tilde{\mathrm{X}}_{\mathrm{ij}}, \mathrm{i}=\right.$ $1,2, \ldots, m, j=1, \ldots, n\}$ for alternatives with respect to criteria. The fuzzy linguistic rating $\tilde{x}_{i j}$ preserves the property that the ranges of normalized triangular fuzzy numbers belong to $[0,1]$; thus, there is no need for normalization.

- Step 2: Considering the different importance values of each criterion, the weighted normalized fuzzy-decision matrix is constructed as:

$$
\widetilde{V}=\left[\tilde{v}_{i j}\right]_{m * n}=\tilde{x}_{i j} * w_{j}, i=1, \ldots, m ; j=1,2, \ldots, n
$$

- $\quad$ Step 3: Identify fuzzy positive-ideal and fuzzy negative ideal solutions as follows:

$$
\begin{array}{r}
A^{*}=\left\{\tilde{v}_{1}{ }^{*}, \tilde{\mathrm{v}}_{2}{ }^{*}, \ldots, \tilde{\mathrm{v}}_{\mathrm{n}}{ }^{*}\right\} \\
\mathrm{A}^{-}=\left\{\tilde{\mathrm{v}}_{1}{ }^{-}, \tilde{\mathrm{v}}_{2}{ }^{-}, \ldots, \tilde{\mathrm{v}}_{\mathrm{n}}{ }^{-}\right\}
\end{array}
$$

where $\widetilde{v}_{\mathrm{j}}^{*}=(1,1,1)$ and $\tilde{\mathrm{v}}_{\mathrm{j}}{ }^{-}=(0,0,0), \mathrm{j}=1,2, \ldots, \mathrm{n}$.

- $\quad$ Step 4: Calculate the distance of each alternative from $A^{*}$ and $\mathrm{A}^{-}$using vertex method as follows:

$$
\begin{array}{cc}
D_{j}^{*}=\sum_{j=1}^{n} d\left(\tilde{v}_{i j}, \widetilde{v}_{j}^{*}\right) & i=1,2, \ldots, m \\
D_{j}^{-}=\sum_{j=1}^{n} d\left(\tilde{v}_{i j}, \widetilde{v}_{j}^{-}\right) & i=1,2, \ldots, m
\end{array}
$$

- Step 5: Calculate similarities to ideal solution:

$$
C_{j}=\frac{D_{j}^{-}}{D_{j}^{*}+D_{j}^{-}} \quad i=1,2, \ldots, m
$$

- Step 6: Choose the alternative with maximum $C_{j}$.

\section{METHOD}

The proposed model for the selection problem consists of the following phases as illustrated in Fig 3.

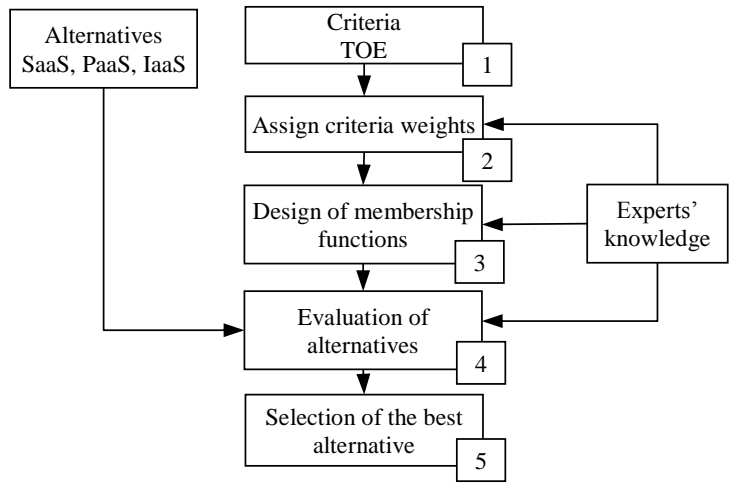

Fig 3. The proposed method. 


\section{Accepted Manuscript: 2017 IEEE International Conference on Fuzzy Systems (FUZZ-IEEE 2017)}

Phase 1: Based on the literature review, this study investigated the determinants focused by the TechnologyOrganization-Environment (TOE) framework to study the decision-making of adopting public cloud computing service models. The hierarchy of criteria is shown in Fig 4.

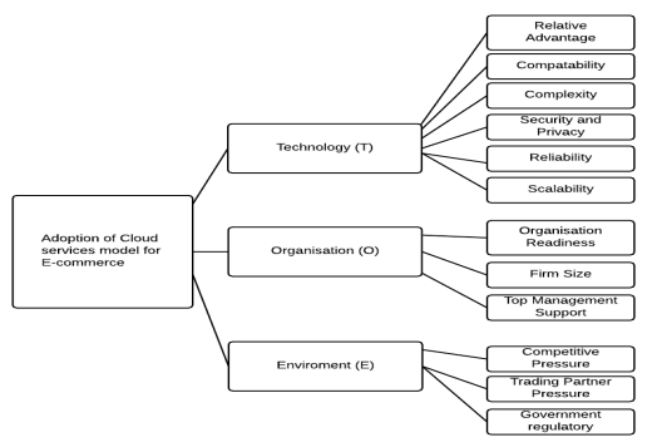

Fig 4. Hierachy of criteria.

Phase 2: In this phase, pairwise comparison matrices are formed to determine the criteria weights. Our expert makes evaluation using a standard scale of nine levels. The scale is provided in Table IV [28]. Using geometric mean technique, the weights and finally the normalized weights are retrieved.

TABLE IV: NINE-POINT INTENSITY OF IMPORTANCE SCALE [28].

\begin{tabular}{ll}
\hline Definition & Intensity of importance \\
\hline Equally important & 1 \\
Moderately more important & 3 \\
Strongly more important & 5 \\
Very strongly more important & 7 \\
Extremely more important & 9 \\
Intermediate values & $2,4,6,8$ \\
\hline
\end{tabular}

Phase 3: Linguistic terms which are used for evaluation of alternatives are explained as in Table V. The membership functions of these linguistic variables are determined as triangular fuzzy numbers for the sake of simplicity as illustrated in Fig 5.

TABLE V: LINGUISTIC VARIABLES

\begin{tabular}{lcc}
\hline \multirow{2}{*}{ Linguistic term } & $\boldsymbol{\alpha}$ level cuts & \\
\cline { 2 - 3 } & 1-level cut & 0-level cut \\
\hline Very Low (VL) & 0 & 0.25 \\
Low (L) & 0.25 & $0,0.5$ \\
Medium (M) & 0.5 & $0.25,0.5$ \\
High (H) & 0.75 & $0.5,1$ \\
Very High (VH) & 1 & 0.75 \\
\hline
\end{tabular}

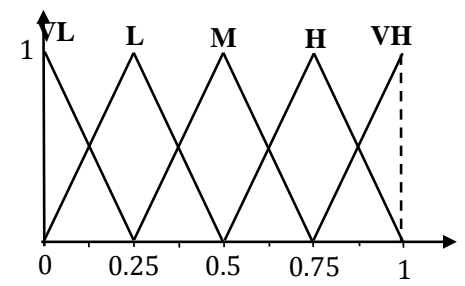

Fig 5. Membership functions of linguistic variables.

Phase 4: Required ranking is obtained by using fuzzy
TOPSIS method in this phase. Linguistic terms determined in the previous phase are used for evaluation of alternatives.

Phase 5: The alternative with the maximum $C_{j}$ is chosen as the optimal strategy according to fuzzy TOPSIS results obtained in Phase 4.

\section{CASE STUDY}

This study intends to suggest the best cloud service model for an e-commerce company. The Company $\mathrm{A}$ is a wellknown B2C online industry in Australia. The name of the company and the experts are preserved to keep the business confidentiality. In this study, a manager was invited to survey three alternatives (SaaS, PaaS and IaaS) using the research model shown in Fig 3.

\section{A. Implementation}

Phase 1 includes 12 evaluation criteria, such as Relative advantage $\left(\mathrm{C}_{1}\right)$, Complexity $\left(\mathrm{C}_{2}\right)$, Compatibility $\left(\mathrm{C}_{3}\right)$, Security \& Privacy $\left(\mathrm{C}_{4}\right)$, Reliability $\left(\mathrm{C}_{5}\right)$, Scalability $\left(\mathrm{C}_{6}\right)$, Organizational readiness $\left(\mathrm{C}_{7}\right)$, Firm size $\left(\mathrm{C}_{8}\right)$, Top management support $\left(\mathrm{C}_{9}\right)$, Competitive pressure $\left(\mathrm{C}_{10}\right)$, Trading partner pressure $\left(\mathrm{C}_{11}\right)$, and Government regulatory environment $\left(\mathrm{C}_{12}\right)$. In Phase 2, the expert is given the task of forming individual pairwise comparison matrix by using the scale given in Table I. Geometric means of these values are obtained and then the normalized weights are calculated as shown in Table VI. In Phase 3, the expert was requested to fill up the decision matrix by evaluating each alternative under each of the criteria. The established fuzzy evaluation matrix by linguistic variables is shown in Table VI.

TABLE VI: FUZZY EVALUATION DECISION MATRIX

\begin{tabular}{ccccc}
\hline Criteria & Weight & SaaS & PaaS & IaaS \\
\hline C1 & 0.07 & VH & H & H \\
C2 & 0.06 & $\mathrm{H}$ & $\mathrm{L}$ & $\mathrm{M}$ \\
C3 & 0.02 & $\mathrm{H}$ & $\mathrm{H}$ & $\mathrm{VH}$ \\
C4 & 0.31 & $\mathrm{VH}$ & $\mathrm{H}$ & $\mathrm{H}$ \\
C5 & 0.21 & $\mathrm{H}$ & $\mathrm{M}$ & $\mathrm{VH}$ \\
C6 & 0.03 & $\mathrm{H}$ & $\mathrm{M}$ & $\mathrm{H}$ \\
C7 & 0.02 & $\mathrm{~L}$ & $\mathrm{H}$ & $\mathrm{VH}$ \\
C8 & 0.06 & $\mathrm{H}$ & $\mathrm{M}$ & $\mathrm{M}$ \\
C9 & 0.18 & $\mathrm{H}$ & $\mathrm{H}$ & $\mathrm{H}$ \\
C10 & 0.01 & $\mathrm{~L}$ & $\mathrm{VL}$ & $\mathrm{VL}$ \\
C11 & 0.02 & $\mathrm{H}$ & $\mathrm{VL}$ & $\mathrm{VL}$ \\
C12 & 0.02 & $\mathrm{~L}$ & $\mathrm{M}$ & $\mathrm{M}$ \\
\hline
\end{tabular}

B. Results

To get the results, in Phase 4, fuzzy TOPSIS is relied upon. According to Table V, it can be seen that the elements $\tilde{\mathrm{v}}_{\mathrm{ij}}$ are normalized positive triangular fuzzy numbers and their ranges belong to the closed interval $[0,1]$. Thus, the fuzzy positive ideal solution $\left(\mathrm{A}^{*}\right)$ and the fuzzy negative-ideal solution $\left(A^{-}\right)$ are considered as $(0,0,0)$ and $(1,1,1)$ for benefit criterion, and $(1,1,1)$ and $(0,0,0)$ for cost criterion. As can be seen, $C_{2}$ is cost criteria whereas the other criteria are benefit criteria in this study. Several matrices are excluded in this paper for space consideration. Fuzzy TOPSIS results are summarized in Table VII. 


\section{Accepted Manuscript: 2017 IEEE International Conference on Fuzzy Systems (FUZZ-IEEE 2017)}

TABLE VII: FUZZY TOPSIS RESULTS.

\begin{tabular}{lccc}
\hline Alternative & $D_{j}^{*}$ & $D_{j}^{-}$ & $C_{j}$ \\
\hline SaaS & 10.299 & 1.727 & 0.144 \\
PaaS & 10.412 & 1.629 & 0.135 \\
IaaS & 10.322 & 1.707 & 0.142 \\
\hline
\end{tabular}

In Phase 5, considering the maximum $C_{j}$, SaaS is chosen as the best option for the given company.

\section{CONCLUSION AND FUTURE WORK}

This paper aims to evaluate technological, organizational, and environmental (TOE) factors of public cloud computing service models (SaaS, PaaS and IaaS) in the context of ecommerce. The selection of cloud-based e-commerce is a typical multiple criteria decision-making (MCDM) problem. Considering the imprecise judgments of decision makers, the fuzzy TOPSIS is used for the evaluation of cloud service models. Finally, observing all the results, fuzzy TOPSIS approach proposes software-as-a-service (SaaS) as the best choice for e-commerce business. The result can give a suggestion to e-commerce managers in the company when decide to migrate online store from on-site to cloud computing environment. The cloud based e-commerce impacts the strength of e-commerce since consolidation is easily afforded between e-commerce Company and cloud provider. This study showed the decision-making process of adopting public clouds and explained the criteria of public cloud adoption in the context of e-commerce, which is helpful for both e-commerce managers and public cloud service providers. It is evident that the TOE criteria could also be applied to solve multiple criteria decision making and evaluation problems in many other fields such as an e-government, and e-health etc.

\section{REFERENCES}

[1] G. Lackermair, "Hybrid cloud architectures for the online commerce," Procedia Computer Science, vol. 3, pp. 550-555, 2011

[2] W. Treesinthuros, "E-commerce transaction security model based on cloud computing," in 2012 IEEE 2nd International Conference on Cloud Computing and Intelligence Systems, 2012, pp. 344-347.

[3] T. Liu, "E-Commerce Application Model Based on Cloud Computing," in 2011 International Conference of Information Technology, Computer Engineering and Management Sciences, 2011, pp. 147-150.

[4] H. L. Qing, "Research on the Model and Application of E-commerce Based on Cloud Computing," in 2012 International Conference on Computer Science and Service System, 2012, pp. 142-146.

[5] P. Mell and T. Grance, "The NIST Definition of Cloud Computing," National Institute of Standards and Technology: U.S. Department of Commerce2011.

[6] X. Wang, "Research on e-commerce development model in the cloud computing environment," in 2012 International Conference on System Science and Engineering (ICSSE), 2012, pp. 539-542.

[7] L. G. Tornatzky and M. Fleischer, Process of technological innovation. Massachusetts/Toronto: Lexington, 1990.

[8] B. Sarwar, G. Karypis, J. Konstan, and J. Riedl, "Analysis of recommendation algorithms for e-commerce," presented at the Proceedings of the 2nd ACM conference on Electronic commerce, Minneapolis, Minnesota, USA, 2000.

[9] E. W. T. Ngai, L. Xiu, and D. C. K. Chau, "Application of data mining techniques in customer relationship management: A literature review and classification," Expert Systems with Applications, vol. 36, pp. 2592-2602, 2009.
[10] T. Islam, Manivannan, D., \& Zeadally, S. , "A Classification and Characterization of Security Threats in Cloud Computing," International Journal of Next-Generation Computing, vol. 7, 2016.

[11] H. H. Zuo and X. Chen, "The Analysis of Storage Efficiency in VMware Virtualization Environment," vol. 697, pp. 438-441, 2015.

[12] A. Thakur. (2015, Dec 2016). Difference between SaaS, PaaS and IaaS explained. http://opensourceforgeeks.blogspot.com.au/2015/01/differencebetween-saas-paas-and-iaas.html

[13] D. Canellos. (2013). How the Internet of Things will Feed Cloud Computing next Evolution. Available: HTTPS://BLOG.CLOUDSECURITYALLIANCE.ORG/2013/06/05/H OW-THE-INTERNET-OF-THINGS-WILL-FEED-CLOUDCOMPUTINGS-NEXT-EVOLUTION/

[14] M. Walterbusch, B. Martens, and F. Teuteberg, "Evaluating cloud computing services from a total cost of ownership perspective," Management Research Review, vol. 36, pp. 613-638, 2013.

[15] B. Ramdani, P. Kawalek, and O. Lorenzo, "Predicting SMEs' adoption of enterprise systems," Journal of Enterprise Information Management, vol. 22, pp. 10-24, 2009.

[16] H. P. Borgman, B. Bahli, H. Heier, and F. Schewski, "Cloudrise: Exploring Cloud Computing Adoption and Governance with the TOE Framework," in 2013 46th Hawaii International Conference on System Sciences, 2013, pp. 4425-4435.

[17] N. Alkhater, R. Walters, and G. Wills, "An investigation of factors influencing an organisation's intention to adopt cloud computing," in International Conference on Information Society (i-Society 2014), 2014, pp. 337-338.

[18] E. M. Rogers, Diffusion of innovations, 5th ed. New York: Free Press, 2003.

[19] F. Safari, N. Safari, A. Hasanzadeh, and A. R. Ghatari, "Factors affecting the adoption of cloud computing in small and medium enterprises," Int. J. Bus. Inf. Syst., vol. 20, pp. 116-137, 2015.

[20] J. Repschläger, S. Wind, R. Zarnekow, and K. Turowski, "Developing a Cloud Provider Selection Model," Lecture Notes in Informatics, vol. 190, pp. 163-176, 2013.

[21] G. Hemlata, D. Hema, and R. Ramaswamy, "Developing a CloudComputing Adoption Framework," Global Business Review, vol. 16, pp. 632-651, 2015.

[22] C.-Y. Tsai, C.-C. Wang, and M.-T. Lu, "Using the technology acceptance model to analyze ease of use of a mobile communication system," Social Behavior and Personality: an international journal, vol. 39, pp. 65-69, 2011.

[23] J. Lu, G. Zhang, and D. Ruan, Multi-objective Group Decision Making: Methods, Software and Applications With Fuzzy Set Techniques: Imperial College Press, 2007.

[24] A. Mardani, A. Jusoh, K. Md Nor, Z. Khalifah, N. Zakwan, and A. Valipour, "Multiple criteria decision-making techniques and their applications - a review of the literature from 2000 to 2014," Economic Research-Ekonomska Istraživanja, vol. 28, pp. 516-571, 2015.

[25] C.-L. Hwang and K. Yoon, Multiple Attribute Decision Making Methods and Applications A State-of-the-Art Survey, 1981.

[26] M. Behzadian, S. Khanmohammadi Otaghsara, M. Yazdani, and J. Ignatius, "A state-of the-art survey of TOPSIS applications," Expert Systems with Applications, vol. 39, pp. 13051-13069, 2012.

[27] P. Wang, Z. Zhu, and Y. Wang, "A novel hybrid MCDM model combining the SAW, TOPSIS and GRA methods based on experimental design," Information Sciences, vol. 345, pp. 27-45, 2016.

[28] M. Dagdeviren, S. Yavuz, and N. Kılınç, "Weapon selection using the AHP and TOPSIS methods under fuzzy environment," Expert Systems with Applications, vol. 36, pp. 8143-8151, 2009.

[29] L. A. Zadeh, "Fuzzy sets," Information and Control, vol. 8, pp. 338353, 1965.

[30] M. Naderpour, J. Lu, and G. Zhang, "An intelligent situation awareness support system for safety-critical environments," Decision Support Systems, vol. 59, pp. 325-340, 2014.

[31] L. A. Zadeh, "The concept of a linguistic variable and its application to approximate reasoning-I," Information Sciences, vol. 8, pp. 199-249, 1975. 